\section{SÍNDROME OBSTRUCTIVO BRONQUIAL AGUDO EN NIÑOS MENORES DE TRES AÑOS EN UN HOSPITAL NACIONAL}

\author{
BRONCHIAL OBSTRUCTIVE SYNDROME ACUTE \\ CHILDREN UNDER THREE YEARS \\ IN A NATIONAL HOSPITAL
}

Nancy Campos-Ramírez ${ }^{1, a}$

Sr. Editor. En nuestro país, las infecciones respiratorias agudas (IRA) constituyen uno de los principales problemas de salud pública, siendo una de las primeras causas de morbilidad y mortalidad infantil, especialmente en niños menores de cinco años constituyendo casi la mitad de las hospitalizaciones, incluyen las bronquitis, bronquiolitis, neumonías y otras afecciones del aparato respiratorio ${ }^{(1)}$.

En mi experiencia personal realice un estudio de tipo prospectivo transversal a 235 niños que acudieron a la sala de emergencia pediátrica del Hospital San José DEL Callao en el año 2010 y que fueron diagnosticados con Síndrome Obstructivo Bronquial Agudo (SOBA).

Para lo cual, previa evaluación clínica, se procedió a llenar una ficha de recolección de datos, donde se consignaron las variables de interés.

Entre los hallazgos más representativos destacaron: el SOBA se presentó mayormente en varones de 2 años a 2 años 11 meses en un 33,6\% del total de niños que participaron en el estudio; mientras que el $52,34 \%$ no presentaron antecedentes de SOBA y el $88 \%$ no presentaron comorbilidades.

El tipo de vivienda más frecuente fue de material noble $(74,46 \%)$. En la exposición a humo de tabaco o tipo de cocina, el $92 \%$ no estuvieron expuestos a humo. La mayor presentación anual se tuvo en los meses de Julio a Septiembre. En el $71 \%$ de pacientes si hubo contacto intradomiciliario con persona con IRA.

En cuanto a la edad promedio de presentación, los resultados obtenidos coinciden con los estudios de Díaz Valenzuela et al. ${ }^{(2)}$ quienes señalan que la edad promedio fue de 3,7 años. Se considera que la presencia de animales constituye un factor de riesgo como contaminante intradomiciliario, debido además al contaminante de las heces de los animales.

Hubo asociación con la exposición al humo de tabaco. El resultado coincide con el obtenido por Rivas et al. ${ }^{(2)}$, que señala que el principal contaminante intradomiciliario es el habito tabáquico de la madre, mientras que en nuestro estudio el principal contaminante fue el tipo de cocina utilizado.

Generalmente la fuente de contagio es intradomiciliario, lo que coincide con los estudios de Rivas et al ${ }^{(3)}$, quienes además señalan que el principal contacto intradomiciliario es la madre del paciente.

Las conclusiones finales del estudio fueron, que el SOBA es una enfermedad que afecta a una gran cantidad de niños entre 2 y 3 años; el número de casos aumenta en la temporada de Invierno, los familiares con antecedente de IRA son un importante factor a considerar en el SOBA y que el principal contaminante es el tipo de cocina utilizado.

\footnotetext{
${ }^{1}$ Facultad de Medicina Humana. Universidad San Luis Gonzaga. Ica, Perú ${ }^{a}$ Médico Pediatra
}

Grafico 1. Frecuencia del Síndrome Obstructivo Bronquial Agudo según edad y sexo.

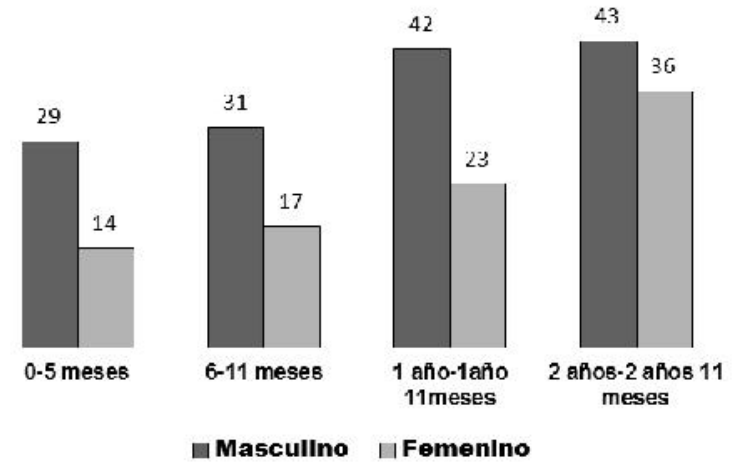

Financiamiento: el estudio fue autofinanciado

Conflictos de interés: el autor declara no tener conflictos de interés en la publicación de este artículo

Correspondencia:

Nancy Campos Ramírez

Correo electrónico:

\section{REFERENCIAS BIBLIOGRÁFICAS}

1. Macri C, Teper A. Enfermedades Respiratorias Pediátricas. Mc Graw Hill. Interamericana. $1^{\circ}$ Edición 2003; 23:201-206 y 70:667-676

2. Díaz GH, Barra BJ, Serrá JA, Mora S, Arroyo MF. Perfil epidemiológico y clínico del paciente con síndrome bronquial obstructivo adosado al programa nacional de prevención y manejo de infecciones respiratorias agudas (IRA) perteneciente a un consultorio de atención primaria. Rev. Ped. Elec. 2006; 3(2).

3. Rivas RE, Barrios CS, Dorner PA, Osorio S X. Fuentes de contaminación intradomiciliaria y enfermedad respiratoria en jardines infantiles y salas cunas de Temuco y Padre Las Casas, Chile. Rev. méd. Chile. 2008 ; 136(6): 767-774.

Recibido: 12/03/2012

Aceptado para publicación: 21/07/2012 